\title{
Prevalence, predictors and clinical implications of prolonged corrected QT in elderly patients with dementia and suspected syncope
}

\author{
Mario Bo $^{\mathrm{a}}$, Alice Ceccofiglio ${ }^{\mathrm{b}}$, Chiara Mussi ${ }^{\mathrm{c}}$, Giuseppe Bellelli ${ }^{\mathrm{d}}$, Franco Nicosia ${ }^{\mathrm{e}}$, Daniela Riccio ${ }^{\mathrm{f}}$, \\ Anna M. Martone ${ }^{g}$, Assunta Langellotto ${ }^{\mathrm{h}}$, Elisabetta Tonon ${ }^{\mathrm{i}}$, Gianni Tava ${ }^{\mathrm{j}}$, Virginia Boccardi ${ }^{\mathrm{k}}$, \\ Pasquale Abete $^{1}$, Michela Tibaldi ${ }^{\mathrm{a}}$, Maria L. Aurucci ${ }^{\mathrm{a}, *}$, Gianfranco Fonte $^{\mathrm{a}}$, Yolanda Falcone ${ }^{\mathrm{a}}$, \\ Andrea Ungar ${ }^{\mathrm{b}}$
}

\footnotetext{
a Section of Geriatrics, Department of Medical Sciences, Città della Salute e della Scienza-Molinette, C Bramante 88, 10126 Torino, Italy

${ }^{\mathrm{b}}$ Syncope Unit, Department of Geriatrics, Azienda Ospedaliero Universitaria Careggi and University of Florence, Florence, Italy

c O.U. of Geriatrics, Department of Biomedical Sciences, Metabolics and Neurosciences, University of Modena and Reggio Emilia, Italy

${ }^{\mathrm{d}}$ Department of Health Sciences, University of Milano Bicocca and Acute Geriatric Unit, San Gerardo Hospital, Monza, Italy

${ }^{\mathrm{e}}$ Medicine and Geriatric Unit - Spedali Civili of Brescia, Brescia, Italy

${ }^{\mathrm{f}}$ Geriatric Department, SS, Trinità Hospital, Cagliari, Italy

${ }^{g}$ Department of Geriatrics, Neurosciences and Orthopedics, Catholic University of the Sacred Heart, Rome, Italy

h S. Maria di Ca' Foncello Hospital, Treviso, Italy

${ }^{\text {i }}$ S. Jacopo Hospital, Azienda USL 3, Pistoia, Italy

${ }^{j}$ Geriatric Unit, Santa Chiara Hospital, Trento, Italy

${ }^{\mathrm{k}}$ Institute of Gerontology and Geriatrics, Department of Medicine, University of Perugia, S. Maria della Misericordia Hospital, Perugia, Italy

${ }^{1}$ Department of Translational Medical Sciences, University of Naples, Federico II, Naples, Italy
}

\section{A R T I C L E I N F O}

\section{Keywords:}

Long QT

QT prolonging drugs

Mortality

Syncope

Dementia

Elderly

\begin{abstract}
A B S T R A C T
Background: Long QT and use of QT-prolonging drugs are common among older patients receiving polytherapies, but real-world evidence on their impact in clinical practice is controversial. We investigated prevalence, variables associated and clinical implications of prolonged corrected QT (QTc) among patients from the Syncope and Dementia study.

Methods: Observational, prospective, multicenter study. Patients $\geq 65$ years with dementia and fall suspected for syncope in the previous three months were enrolled. Several clinical variables and the complete list of medications were recorded for each patient. A 12-lead ECG was obtained and corrected QT was calculated by the Bazett's formula. One-year followup for death and recurrent syncope was performed.

Results: Prolonged QTc was observed in $25 \%$ of the 432 enrolled patients (mean age 83.3), and was significantly associated with male gender (OR 2.09; 95\% CI 1.34-3.26) and diuretics use (OR 1.85; 95\% CI 1.18-2.90). At one-year $23.3 \%$ of patients died and $30.4 \%$ reported at least one recurrent event. Variables associated with oneyear mortality were: age, male gender, atrial fibrillation (AF), use of calcium channel blockers and prolonged QTc (OR 1.80; 95\% CI 1.01-3.20). Among patients with prolonged QTc a significant interaction for mortality was found with AF. Recurrent events were associated with the use of antiplatelets, cholinesterase.

inhibitors and antipsychotics, but not with prolonged QTc.

Conclusions: We documented a high prevalence of prolonged QTc, that was associated with male gender and diuretics but not with psychoactive medications. Patients with prolonged QTc had higher one-year mortality, that was four-fold increased in those with concomitant AF.
\end{abstract}

\section{Introduction}

Long QT syndrome is an electro-physiologic disorder in which the ventricular repolarization is lengthened, with an increased susceptibility to ventricular tachy-arrhythmias, potentially leading to syncope, cardiac arrest and sudden cardiac death [1]. Acquired prolonged QT interval is the most common form of long QT syndrome, and usually results from the complex interplay between several factors

\footnotetext{
* Corresponding author at: C.so Bramante 88, 10126 Turin, Italy.

E-mail address: marialuigia.aurucci@unito.it (M.L. Aurucci).
} 
including electrolyte imbalance, cardiac ischemia and structural heart disease and drugs [1,2].

Older age by itself is a risk factor for QT prolongation [3-7]; moreover age-associated conditions such as presence of dementia and polypharmacy make elderly patients at increased exposure to QT prolonging drugs and consequently at risk of adverse associated outcomes $[8,9]$. However, to the best of our knowledge, there are limited data about prevalence and prognostic implications of prolonged QT in real-world older patients.

The "Syncope and Dementia" study (SYD) was designed by the Italian Group for the study of Syncope with the endorsement of the Italian Geriatric Society in order to evaluate older patients with dementia and suspected syncope or unexplained falls [10]. Advanced age, the presence of dementia and the use of multiple medications, including antipsychotics and antidepressants, make these patients a potentially interesting target to investigate prevalence and clinical implications of prolonged QTc (corrected QT).

Accordingly, the aims of the present study were: i) to investigate prevalence and variables associated with prolonged QTc in older patients with dementia, and ii) to evaluate whether prolonged QTc was associated with death and recurrence of syncope and falls at one-year.

\section{Methods}

This is a secondary analysis of the SYD [10] dataset, that was a prospective observational study involving nine Italian departments of Geriatrics. The overall study population consisted of 522 in- and outpatients aged $\geq 65$ years referring to acute care wards, syncope units or Alzheimer's evaluation units. The full study design, including the standardized multidimensional geriatric assessment and the diagnostic protocol applied for the diagnosis and management of syncope, has been described elsewhere $[10,11]$. Briefly, consecutive patients with a diagnosis of dementia, according to the Diagnostic and Statistical Manual of Mental Disorders IV [12], and at least one episode of suspected syncope or unexplained fall during the previous three months, were enrolled. Informed consent was obtained from each patient. The study protocol was approved by the Ethic Committee of the University of Naples and then by each local ethical committee.

At their first visit patients underwent a full diagnostic evaluation, including a 12-leads-ECG, which was tape-recorded for further revision. The QT interval was measured from the onset of QRS complex to the end of the $\mathrm{T}$ wave (the intersection between the $\mathrm{T}$ wave tangent, drawn at its maximum down slope, and the isoelectric line), and corrected for the previous cardiac cycle length according to the Bazett's formula [13]. An averaged QT measure over 3 to 5 beats in a single lead was calculated both in patients with sinus rhythm and in those presenting with atrial fibrillation (AF) [14] preferably using either lead II or lead V5. All measurements where revised by an experienced cardiologist (MB). Patients with pace-maker and subjects without valid QTc measurements were excluded from this analysis. Prolonged QTc was defined using a threshold value of 450 milliseconds (ms) in males and $460 \mathrm{~ms}$ in females [15].

The presence of comorbidities was investigated and their number and severity were scored according to the Cumulative Illness Rating Scale (CIRS) [16,17]. A complete list of pharmacological treatment, coded according to the Anatomical Therapeutic and Chemical codes [18] was collected for each patient; particular attention was given to medications potentially prolonging QTc interval, including antipsychotics and antidepressants [19].

One year follow-up was conducted through planned visit or phone interviews with patients' main caregiver, aiming to ascertain vital status and recurrence of syncope or unexplained falls. For patients reporting recurrent clinical events, medical documentation was obtained in order to confirm the diagnosis.

Mean and standard deviation (SD) for continuous variables and percentage for dichotomous variables were calculated. Variables associated with prolonged QTc were evaluated at univariate analysis using the $\chi^{2}$ test for categorical variables and the ANOVA for continuous variables. Significant variables at univariate analysis were then introduced in a logistic regression model in order to identify those independently associated with prolonged QTc.

Variables associated with clinical outcomes (death and recurrent syncope or unexplained fall), including the presence of prolonged QTc, were identified at univariate analysis using the $\chi^{2}$ test for dichotomous variables and ANOVA for continuous variables. Variables that achieved the level of significance at univariate analysis where then introduced in a stepwise multiple logistic model, in order to identify those independently associated with mortality and recurrent events at one year (multivariate analysis, model 1). To test potential interactions with prolonged QTc, variables significantly associated with mortality among patients with prolonged QTc were identified, and then introduced in a second multivariate analysis together with significant variables evaluated in the first model (multivariate analysis, model 2).

All statistical analysis were performed using the Software SPSS/ $\mathrm{PC}+$. Statistical significance was set at $p \leq .05$.

\section{Results}

From February 2012 to October 2016, a total of 522 patients were enrolled in the SYD study. Subjects without valid QTc measurements were excluded, leaving a sample of 432 patients available for this study. Main demographic and clinical characteristics of the overall sample of patients and in those with and without prolonged QTc are reported in Table 1 . In the overall sample, mean age was $83.3 \pm 6.2$ years and $38.7 \%$ were males, with high prevalence of comorbidities and poor level of basic and instrumental functional autonomy (Activities of Daily Living scale (ADL) and Instrumental Activities of Daily Living scale (IADL). The mean number of daily taken drugs was of $5.98 \pm 2.81$; psychoactive medications were widely used, including antipsychotics (24.5\%), antidepressants (33.8\%) and benzodiazepines (21.3\%). The average heart rate was $74.4 \pm 15.1$, and AF was present in $14.4 \%$ of patients. The mean QTc length was $436.1 \pm 26.6 \mathrm{~ms}$ and prolonged QTc was observed in $25 \%$ of patients.

At univariate analysis, prolonged QTc was associated with male gender $(p=.001)$, use of diuretics $(p=.008)$ and insulin $(p=.024)$, orthostatic hypotension $(p=.006)$, AF $(p=.037)$, heart rate $(p<.0001)$ and CIRS Severity Index $(p=.01)$ (Table 1$)$. After stepwise multiple linear regression analysis, only male gender (Odds Ratio (OR) 2.09, 95\% CI 1.34-3.26) and diuretic use (OR 1.85, 95\% CI 1.18-2.9) were significantly associated with a prolonged QTc.

Complete follow-up data at one year were not available for 77 patients, who were excluded from further analysis. Among the 355 remaining patients, 83 patients (23.3\%) died (35.6\% among patients with prolonged QTc and $19.3 \%$ among patients with normal QTc), while recurrence of syncope or unexplained fall was observed in 108 patients (30.4\%). Variables associated with one-year mortality and recurrence of syncope or unexplained fall are reported in Table 2. After stepwise multiple logistic model analysis (model 1) prolonged QTc was significantly associated with all-cause mortality at one-year (OR 1.80; 95\% CI 1.01-3.20), along with age, male gender, AF and use of calcium channel blockers (Table 3).

Among patients with prolonged QTc, several variables were significantly associated with one-year mortality: male gender (OR 3.97; 95\% IC 2.10-7.52), congestive heart failure (OR 5.24; $95 \%$ IC 1.44-19.04), AF (OR 6.42; 95\% IC 2.44-16.91), anticoagulants (OR 3.47; 95\% IC 1.07-11.17), age (OR 1.01; 95\% IC 1.00-1.18), ADL score (OR 1.22; 95\% IC 1.08-1.38), CIRS Severity Index (OR 1.64; 95\% IC 1.21-2.22) and CIRS Comorbidity Index (OR 1.22; 95\% IC 1.08-1.39). After introducing significant variables in the stepwise multiple logistic model analysis (model 2) only the interaction between the presence of $\mathrm{AF}$ and prolonged QTc was found to be significantly associated with death, along with male gender, age and use of calcium channel blockers 
Table 1

Clinical and demographical variables of the overall study sample, and in patients with and without prolonged QTc.

\begin{tabular}{|c|c|c|c|c|}
\hline Characteristics & $\begin{array}{l}\text { Overall } \\
(n=432)\end{array}$ & $\begin{array}{l}\text { Long QTc } \\
(n=108)\end{array}$ & $\begin{array}{l}\text { Normal QTc } \\
(n=324)\end{array}$ & $\mathrm{p}$ \\
\hline Age, years, mean \pm SD & $83.3 \pm 6.2$ & $83.7 \pm 6.2$ & $83.1 \pm 6.2$ & 0.39 \\
\hline Heart rate, mean $\pm \mathrm{SD}$ & $74.4 \pm 15.1$ & $79.6 \pm 15.0$ & $72.7 \pm 5.1$ & 0.00003 \\
\hline MMSE score, mean \pm SD & $16.6 \pm 5.6$ & $16.2 \pm 5.6$ & $16.7 \pm 5.6$ & 0.38 \\
\hline CIRS SI, mean \pm SD & $1.6 \pm 0.4$ & $1.7 \pm 0.4$ & $1.6 \pm 0.4$ & 0.01 \\
\hline CIRS CI, mean \pm SD & $3.2 \pm 1.9$ & $3.4 \pm 1.9$ & $3.1 \pm 1.9$ & 0.2 \\
\hline Number of drugs, mean \pm SD & $6.0 \pm 2.8$ & $6.2 \pm 2.8$ & $5.9 \pm 2.8$ & 0.35 \\
\hline Male sex & $167(38.7)$ & $56(51.9)$ & $111(34.3)$ & 0.001 \\
\hline ADL, patients with $>2$ lost functions, $\mathrm{n}(\%)$ & $258(59.7)$ & $67(62.0)$ & $191(59.0)$ & 0.57 \\
\hline IADL, patients with $>3$ lost functions, n (\%) & $357(82.6)$ & $93(86.1)$ & $264(81.5)$ & 0.27 \\
\hline Stroke, Transient Ischemic Attack (TIA), n (\%) & $106(24.5)$ & $29(26.9)$ & $77(23.8)$ & 0.52 \\
\hline Psychiatric disorders, n (\%) & $139(32.2)$ & $30(27.8)$ & $109(33.6)$ & 0.26 \\
\hline Depressive symptoms, n (\%) & $117(27.1)$ & $24(22.2)$ & $95(29.3)$ & 0.15 \\
\hline Major depressive disorder, $\mathrm{n}(\%)$ & $32(8.1)$ & $8(7.4)$ & $24(7.4)$ & 1 \\
\hline Cardiovascular diseases, $\mathrm{n}(\%)$ & $389(90.0)$ & $98(90.7)$ & $291(89.8)$ & 0.78 \\
\hline Hypertension, $\mathrm{n}(\%)$ & 318 (73.6) & $83(76.9)$ & $237(73.1)$ & 0.45 \\
\hline Orthostatic hypotension, n (\%) & $47(10.9)$ & $4(3.7)$ & $43(13.3)$ & 0.006 \\
\hline Coronary artery disease, $\mathrm{n}(\%)$ & $75(17.4)$ & $22(20.4)$ & $53(16.4)$ & 0.34 \\
\hline Congestive heart failure, $\mathrm{n}(\%)$ & $30(6.9)$ & $11(10.2)$ & $19(5.9)$ & 0.13 \\
\hline Atrial fibrillation, $\mathrm{n}(\%)$ & $62(14.4)$ & $22(20.4)$ & $40(12.3)$ & 0.04 \\
\hline Carotid plaques, n (\%) & $110(25.5)$ & $24(22.2)$ & $86(26.5)$ & 0.37 \\
\hline Types II diabetes mellitus, n (\%) & $91(21.1)$ & $29(26.9)$ & $62(19.1)$ & 0.09 \\
\hline Thyroid dysfunction, $\mathrm{n}(\%)$ & $45(10.4)$ & $8(7.4)$ & $37(11.4)$ & 0.24 \\
\hline Diuretics, n (\%) & $154(35.6)$ & $50(46.3)$ & $104(32.1)$ & 0.01 \\
\hline Angiotensin-converting enzyme inhibitors, $\mathrm{n}(\%)$ & $150(34.7)$ & $36(33.3)$ & $114(35.2)$ & 0.73 \\
\hline Angiotensin receptor blockers, $\mathrm{n}(\%)$ & $67(15.5)$ & $16(14.8)$ & $51(15.7)$ & 0.82 \\
\hline Calcium channel blockers, n (\%) & $77(17.8)$ & $19(17.6)$ & $58(17.9)$ & 0.94 \\
\hline Alpha-blockers, n (\%) & $57(13.2)$ & $18(16.7)$ & $39(12.0)$ & 0.22 \\
\hline Beta-blockers, n (\%) & $107(24.8)$ & $30(27.8)$ & 77 (23.8) & 0.40 \\
\hline Nitrates, n (\%) & $40(9.3)$ & $9(8.3)$ & $31(9.6)$ & 0.70 \\
\hline Anti-arrhythmics, n (\%) & $32(7.4)$ & $12(11.1)$ & $20(6.2)$ & 0.09 \\
\hline Digoxin, $\mathrm{n}(\%)$ & $24(5.6)$ & $5(4.6)$ & $19(5.9)$ & 0.63 \\
\hline Antiplatets, n (\%) & $240(55.6)$ & $58(53.7)$ & $182(56.2)$ & 0.65 \\
\hline Anticoagualants, n (\%) & $53(12.3)$ & $15(13.9)$ & $38(11.7)$ & 0.55 \\
\hline Insulin, $\mathrm{n}(\%)$ & $28(6.5)$ & $12(11.1)$ & $16(4.9)$ & 0.02 \\
\hline Oral glucose lowering drugs, n (\%) & $57(13.2)$ & $16(14.8)$ & $41(12.7)$ & 0.57 \\
\hline Levothyroxine, n (\%) & $26(61.9)$ & $4(3.7)$ & $22(6.8)$ & 0.24 \\
\hline Benzodiazepines, n (\%) & $92(21.3)$ & $25(23.1)$ & $67(20.7)$ & 0.59 \\
\hline Anticonvulsants, n (\%) & $30(6.9)$ & $6(5.6)$ & $24(7.4)$ & 0.51 \\
\hline Antipsychotics, n (\%) & $106(24.5)$ & $26(24.1)$ & $80(24.7)$ & 0.90 \\
\hline Antidepressants, n (\%) & $146(33.8)$ & $37(34.3)$ & $109(33.6)$ & 0.91 \\
\hline Antiparkinsonians, n (\%) & $44(10.2)$ & $7(6.5)$ & $37(11.4)$ & 0.14 \\
\hline Non-steroidal anti-inflammatory, $\mathrm{n}(\%)$ & $20(4.6)$ & $4(3.7)$ & $16(4.9)$ & 0.60 \\
\hline Cholinesterase inhibitors, $\mathrm{n}(\%)$ & $62(13.4)$ & $11(10.2)$ & $51(15.7)$ & 0.15 \\
\hline Memantine, n (\%) & $34(7.9)$ & $7(6.5)$ & $27(8.3)$ & 0.54 \\
\hline
\end{tabular}

QTc: corrected QT; ADL: Acitivities of Daily Living scale; IADL: Instrumental Acitivities of Daily Living scale; MMSE: Mini Mental State Examination; CIRS SI: Cumulative Illness Rating Scale Severity Index; CIRS CI: Cumulative Illness Rating Scale Comorbidity Index.

\section{(Table 3).}

No association was observed between prolonged QTc and recurrence of syncope or unexplained fall, which were significantly associated with the use of antiplatelets (OR 1.72; 95\% CI 1.07-2.76), cholinesterase inhibitors (OR 1.86; 95\% CI 1.01-3.44) and antipsychotics (OR 1.84; 95\% CI 1.11-3.07).

\section{Discussion}

In a sample of older patients admitted for syncope or unexplained falls we observed these main clinical findings: i) a high prevalence of prolonged QTc interval, with one fourth of patients affected; ii) a significant association of prolonged QTc with male gender and diuretic use, but not with other specific drug-classes, including antipsychotics; iii) prolonged QTc (along with male gender, increasing age, use of calcium channel blockers and AF) was associated with higher one-year mortality, with a four-fold increased risk in patients with concomitant AF.

The prevalence of prolonged QTc observed in our sample is in keeping with previous studies. Among 537 medical inpatients $(70 \%$ aged over 65 years), Pasquier et al. observed a prevalence of prolonged
QT of 22.3\% [20], whereas Maison and colleagues reported a prevalence of $22 \%$ in a sample of older hospitalized patients, with a mean age of 87 years [21].

With respect to determinants of prolonged QTc, several factors have been reported in literature [22,23], including advancing age, female gender and drug therapies. Although QT interval is usually longer in adult women than in men until the sixth decade [5,24], only few studies have investigated QT length in older patients [23]. In our sample of elderly patients, we observed an association between male sex and prolonged QTc (OR 2.09, 95\% CI 1.34-3.26). Our findings are in keeping with the study of Maison et al., that reported an increased prevalence of prolonged QT in older males (OR 3.25, 95\%CI 1.43-7.41) [21]. Age-associated modifications of sex-steroid hormones might affect cardiac repolarization; several studies have reported that lower levels of testosterone were associated with longer QTc interval. [25-27].

In a sample of older patients with high prevalence of polypharmacy and wide use of several drugs with potential QT prolonging effect, only diuretics were significantly associated with prolonged QTc. More than one-third of study patients were treated with diuretics, mainly thiazides and furosemide. This association could be explained by diuretics effects on potassium homeostasis $[3,7,28,29]$, even if a causal relationship is 
Table 2

Variables associated with death and recurrence of syncope or unexplained fall: univariate analysis.

\begin{tabular}{|c|c|c|c|c|c|c|}
\hline & Dead $(n=83)$ & Alive $(n=272)$ & $\mathrm{p}$ & $\begin{array}{l}\text { Recurrence of syncope/unexplained fall } \\
(\mathrm{n}=108)\end{array}$ & $\begin{array}{l}\text { Not recurrence of syncope/unexplained } \\
\text { fall }(n=247)\end{array}$ & $\mathrm{p}$ \\
\hline Age, years, mean $\pm S D$ & $84.1 \pm 5.9$ & $82.5 \pm 6.3$ & 0.03 & $82.8 \pm 6.0$ & $82.9 \pm 6.3$ & 0.90 \\
\hline Heart rate, mean $\pm S D$ & $79.7 \pm 16.6$ & $73.2 \pm 14.4$ & 0.001 & $73.7 \pm 14.2$ & $75.1 \pm 15.5$ & 0.45 \\
\hline ADL score, mean \pm SD & $3.5 \pm 2.1$ & $2.9 \pm 2.0$ & 0.01 & $3.1 \pm 2.0$ & $3.0 \pm 2.1$ & 0.58 \\
\hline Number of drugs, mean $\pm S D$ & $6.0 \pm 2.7$ & $6.0 \pm 2.9$ & 0.97 & $6.5 \pm 2.9$ & $5.8 \pm 2.8$ & 0.03 \\
\hline CIRS SI, mean \pm SD & $1.7 \pm 0.3$ & $1.6 \pm 0.4$ & 0.006 & $1.57 \pm 0.4$ & $1.6 \pm 0.4$ & 0.47 \\
\hline CIRS CI, mean \pm SD & $3.6 \pm 1.9$ & $3.1 \pm 1.9$ & 0.06 & $3.2 \pm 1.9$ & $3.3 \pm 1.9$ & 0.77 \\
\hline Sex & & & 0.0001 & & & 0.10 \\
\hline Male, n (\%) & $34(41.0)$ & $183(67.3)$ & & $73(67.6)$ & $144(58.3)$ & \\
\hline Female, n (\%) & $49(59.0)$ & $89(32.7)$ & & $35(32.4)$ & $103(41.7)$ & \\
\hline QTc length & & & 0.002 & & & 0.51 \\
\hline Prolonged, n (\%) & $31(37.3)$ & $56(20.6)$ & & $24(22.2)$ & $63(25.5)$ & \\
\hline Normal, n (\%) & $52(62.7)$ & $216(79.4)$ & & $84(77.8)$ & $184(74.5)$ & \\
\hline $\mathrm{ADL}$ & & & 0.002 & & & 0.75 \\
\hline $\begin{array}{l}\text { Patients with }>2 \text { lost functions, } \mathrm{n} \\
\text { (\%) }\end{array}$ & $21(25.3)$ & $58(21.3)$ & & 15 (13.9) & $87(35.2)$ & \\
\hline $\begin{array}{l}\text { Patients with }<2 \text { lost functions, } \mathrm{n} \\
\text { (\%) }\end{array}$ & $62(74.7)$ & 214 (78.7) & & $93(86.1)$ & $160(64.8)$ & \\
\hline IADL & & & 0.061 & & & 0.56 \\
\hline $\begin{array}{l}\text { Patients with }>3 \text { lost functions, } \mathrm{n} \\
\text { (\%) }\end{array}$ & $7(8.4)$ & $72(26.5)$ & & $9(8.3)$ & $93(37.7)$ & \\
\hline $\begin{array}{l}\text { Patients with }<3 \text { lost functions, } \mathrm{n} \\
\text { (\%) }\end{array}$ & 76 (91.6) & $200(73.5)$ & & 99 (91.7) & $154(62.3)$ & \\
\hline Psychiatric disorders & & & 0.02 & & & 0.80 \\
\hline Present, n (\%) & $18(21.7)$ & $97(35.7)$ & & $36(33.3)$ & $79(32.0)$ & \\
\hline Absent, n (\%) & $65(78.3)$ & $175(64.3)$ & & $72(66.7)$ & $168(68.0)$ & \\
\hline Depressive symptoms & & & 0.65 & & & 0.11 \\
\hline Present, n (\%) & $6(7.2)$ & $24(8.8)$ & & $13(12.0)$ & $17(6.9)$ & \\
\hline Absent, n (\%) & $77(92.8)$ & $248(91.2)$ & & $95(88.0)$ & $230(93.1)$ & \\
\hline Congestive heart failure & & & 0.02 & & & 0.40 \\
\hline Present, n (\%) & $11(13.3)$ & $15(5.5)$ & & $6(5.6)$ & $20(8.1)$ & \\
\hline Absent, n (\%) & $72(86.7)$ & $257(94.5)$ & & $102(94.4)$ & $227(91.9)$ & \\
\hline Atrial fibrillation & & & 0.003 & & & 0.46 \\
\hline Present, n (\%) & $20(24.1)$ & $30(11.0)$ & & $13(12.0)$ & $37(15.0)$ & \\
\hline Absent, n (\%) & $63(75.9)$ & $242(89.0)$ & & $95(88.0)$ & $210(85.0)$ & \\
\hline Carotid plaques & & & 0.49 & & & 0.04 \\
\hline Present, n (\%) & $18(21.7)$ & $69(25.4)$ & & 34 (31.5) & $53(21.5)$ & \\
\hline Absent, n (\%) & $65(78.3)$ & $203(74.6)$ & & 74 (68.5) & $194(78.5)$ & \\
\hline Calcium channel blockers & & & 0.05 & & & 0.05 \\
\hline Present, n (\%) & $21(25.3)$ & $43(15.8)$ & & $13(12.0)$ & $51(20.6)$ & \\
\hline Absent, n (\%) & $62(74.7)$ & $229(84.2)$ & & 95 (88.0) & $196(79.4)$ & \\
\hline \multicolumn{7}{|l|}{ Antiplatelets } \\
\hline Present, n (\%) & $44(53.0)$ & $154(56.6)$ & & $70(64.8)$ & $128(51.8)$ & \\
\hline Absent, n (\%) & $39(47.0)$ & $118(43.4)$ & 0.56 & $38(35.2)$ & $119(48.2)$ & 0.02 \\
\hline Anticoagulants & & & 0.02 & & & 0.28 \\
\hline Present, n (\%) & $16(19.3)$ & 27 (9.9) & & $10(9.3)$ & $33(13.4)$ & \\
\hline Absent, n (\%) & $67(80.7)$ & $245(90.1)$ & & $98(90.7)$ & $214(86.6)$ & \\
\hline Antipsychotics & & & 0.57 & & & 0.01 \\
\hline Present, n (\%) & $23(27.7)$ & $67(24.6)$ & & $37(34.3)$ & $53(21.5)$ & \\
\hline Absent, n (\%) & $60(72.3)$ & $205(75.4)$ & & $71(65.7)$ & $194(78.5)$ & \\
\hline Cholinesterase inhibitors & & & 0.06 & & & 0.03 \\
\hline Present, n (\%) & $7(8.4)$ & $46(16.9)$ & & $23(21.3)$ & $30(12.1)$ & \\
\hline Absent, n (\%) & 76 (91.6) & $226(83.1)$ & & $85(78.7)$ & 217 (87.9) & \\
\hline
\end{tabular}

ADL: Acitivities of Daily Living scale; IADL: Instrumental Acitivities of Daily Living scale; CIRS SI: Cumulative Illness Rating Scale Severity Index; CIRS CI: Cumulative Illness Rating Scale Comorbidity Index; QTc: corrected QT.

Table 3

Variables significantly associated with one-year mortality (Model 1and Model 2).

\begin{tabular}{|c|c|c|c|c|c|c|c|c|c|c|}
\hline & \multicolumn{5}{|c|}{ Model 1} & \multicolumn{5}{|c|}{ Model 2} \\
\hline & ß & $\operatorname{SE}(ß)$ & OR & $95 \%$ IC & $\mathrm{p}$ & 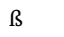 & $\operatorname{SE}(ß)$ & OR & $95 \%$ IC & $\mathrm{p}$ \\
\hline Male sex & 1.22 & 0.28 & 3.38 & $1.94-5.89$ & 0.000 & 1.25 & 0.28 & 3.49 & $2.01-6.07$ & 0.000 \\
\hline Atrial fibrillation & 0.68 & 0.35 & 1.98 & $1.15-4.13$ & 0.05 & - & - & - & - & - \\
\hline Calcium channel blockers & 0.78 & 0.33 & 2.18 & $1.00-3.89$ & 0.02 & 0.82 & 0.32 & 2.26 & $1.20-4.27$ & 0.01 \\
\hline Prolonged QTc & 0.59 & 0.30 & 1.80 & $1.01-3.20$ & 0.05 & - & - & - & - & - \\
\hline Age & 0.06 & 0.06 & 1.06 & $1.02-1.11$ & 0.001 & 0.07 & 0.02 & 1.07 & $1.02-1.12$ & 0.004 \\
\hline Prolonged QTc with concomitant AF & - & - & - & - & - & 1.53 & 0.52 & 4.62 & $1.68-2.75$ & 0.003 \\
\hline
\end{tabular}

QTc: corrected QT; AF: Atrial Fibrillation. 
not defined. It has been suggested that QT interval prolongation might be at least in part due to diuretic-induced hypomagnesemia, but there are no definite data at this regard [22,29]. Certainly both conditions are very frequent in older individuals, that are particularly vulnerable to the depleting effects of diuretics.

In this sample of older patients with dementia, antipsychotic drugs, although widely used, were not associated with prolonged QTc interval. Results did not differ analyzing separately typical and atypical antipsychotic drugs (data not shown). Although there is no doubt that antipsychotic drugs have the potential to cause arrhythmias, the ion channel effects of most drugs are relatively weak [30-33], and it is possible that these medications do not intrinsically prolong the QTc interval [34]. Moreover, QTc by itself is a weak predictor of torsade de pointes and sudden cardiac death [35], and there is no clear consensus on the correct approach for managing QT-prolonging risk with antipsychotics [30]. However, in the present study we were not able to identify sudden death events, thereby reducing clinical implications of present findings.

In our analysis prolonged QTc, and QTc prolongation with concomitant AF, were associated with a two-fold and more than four-fold increased risk of all-cause mortality, respectively. Our findings add on and reinforce previous studies which demonstrated that long QTc is a risk factor for all-cause mortality [23,28,34]. Several studies confirmed this association among adult patients in different clinical settings, with risk of all-cause mortality approximately triplicated, as well in older patients [36-40]. Pickham et al. [36] reported a risk of all-cause mortality approximately triplicated in a cohort of intensive care unit adult patients. Nakanishi et al. [37] demonstrated that individuals with prolonged QT have a two-fold increased risk of death in a sample of 3543 elderly Japanese patients. In the Rotterdam study (3484 patients, mean age 69.1, SD 8.1 years) QT prolongation was associated with a two-fold increased risk of mortality, with a significant increased risk of sudden cardiac death only in participants with a consistently prolonged QT defined as presence of a prolonged QT on two consecutive electrocardiograms [39]. However, some of these studies [37,40] excluded patients who were taking medications potentially associated with increased risk of prolonged QT, and no study used a comprehensive multidimensional evaluation; present findings, demonstrating a significant association of prolonged QTc with mortality on top of a standardized cardiologic protocol and a multidimensional geriatric assessment, confirm the robustness and strength to this association.

In our study, $\mathrm{AF}$ was found to be an important risk factor for death in both models, and QTc prolongation with concomitant AF was associated with a more than four-fold increased risk of mortality. Concomitant prolonged QTc interval and AF might be expression of an increased severity of structural cardiac disease, thereby underlying increased individual vulnerability and risk of death. Moreover, the presence of both these conditions has been reported to be associated with a five-fold enhanced risk of heart failure [41]. Unfortunately, we were not able to ascertain the cause of death in study patients; further prospective studies should address this causal association in older polymorbid patients.

Calcium channel blockers were the only drug class associated with a statistically significant increased risk of mortality in our study, which was more than doubled in patients receiving these drugs (OR 2.18 and OR 2.26 in model 1 and model 2, respectively). In literature there is scant evidence about this issue and, moreover, in our study calcium channel blockers were considered all together, without differentiating between dihydropyridinic and non-dihydropyridinic ones. Data are intriguing but despite the observational prospective design, the comprehensive multidimensional assessment and the statistical analysis, we can't definitively exclude a chance result.

Finally, prolonged QTc interval was not significantly associated with recurrent events, which were significantly more frequent in patients treated with antiplatelet drugs, cholinesterase inhibitors and antipsychotics. Use of cholinesterase inhibitors and antipsychotics might suggest a more advanced stage of dementia, with behavioral symptoms, thereby portending an increased risk of recurrent events, mainly falls. It is more difficult to find explanations for the observed association of antiplatelet drugs with recurrent events, which remained significant after correcting for cardiovascular variables such as history of stroke, TIA or ischemic heart disease. Use of antiplatelet drugs might be a surrogate of perceived increased risk of cardiovascular events or of vascular dementia, this latter being associated with an increased risk of falls. However, a causal relation seems unlikely.

In our view, the present prospective study has several strengths, including the multicenter enrollment, the standardized cardiologic evaluation and the comprehensive multidimensional geriatric assessment. Therefore, patients enrolled may be considered representative of the vast group of real world older in- and out-patients with dementia admitted for suspected syncope. For the same reasons, these findings should not be generalized to "healthier" elderly subjects without cognitive impairment and with better clinical and functional status. Some limitations should be considered too. Firstly, we were not able to ascertain specific cause of death in all patients and, therefore, we could not discriminate how much sudden cardiac death contributed to overall mortality and whether prolonged QTc was associated also with increased risk of sudden death, thus potentially reducing clinical implications of the present findings. However, the principal aim of this study was to evaluate whether QTc prolongation was significantly associated with increased overall mortality (or recurrent events), despite the multiple concurrent potential causes of death and falls among these older and vulnerable patients. Secondly, as discussed above, we could not evaluate potential modifications of QTc length during follow up, thereby making impossible to ascertain whether further prolonging of QTc length occurred in patients with adverse outcomes. Therefore, despite the well documented potential causal link and the independent association observed, whether QTc interval prolongation is a risk factor for, rather than a marker of, increased mortality risk in these patients remains a matter of discussion. Although other formulas are available for QTc measurement, the Bazett's formula (which does not correct for gender and might under- and overestimate QTc at very low and very high heart rate) is currently one of the most widely used in clinical practice. By the way, in our sample of patients medium heart rate was 74.4 , and only 78 patients $(18 \%)$ had heart rate lower than $60 \mathrm{bpm}$ or higher than $100 \mathrm{bpm}$. Indeed, results did not significantly change when the analysis was performed using the method proposed by Sagie et al. [42]. Moreover, although the severity of QT prolongation has clinical relevance, we deliberately did not consider the association between absolute QTc intervals and prolonged QTc, since in clinical practice physicians usually rely on prolonged QTc rather than on its absolute value.

Despite these limitations, our findings have potential clinical implications. Dementia and cognitive impairment are common chronic conditions affecting older individuals and, in these patients, falls and suspected syncope are frequent cause of admission to hospital [43-45]. Most of these vulnerable patients usually are treated with one or more psychoactive medications and other concomitant drug therapy potentially associated with QTc prolonging effect [30,46]. Our findings suggest that diuretics, rather than antipsychotics, are closely associated with prolonged QTc in these patients. Therefore, present findings suggest the need of a careful and inclusive review of all drug therapies potentially implicated with prolonged QTc and of regular ECG monitoring in these older patients receiving polypharmacy.

\section{Conclusions}

In this cohort of older patients with dementia and suspected syncope, we demonstrated a high prevalence of prolonged QTc, that was associated with male gender and diuretic use. QTc prolongation, by itself and with concomitant AF, was associated with a two-fold and four-fold increased risk of mortality, respectively. 


\section{Conflict of interest}

The authors have no conflicts of interest to declare.

\section{Funding sources}

This research did not receive any specific grant from funding agencies in the public, commercial, or not-for-profit sectors.

\section{Author contributions}

Ungar, Mussi, Ceccofiglio, Bellelli, Nicosia, Bo, Abete: conception and design, acquisition of data, analysis and interpretation of data, drafting article or revising it critically for important intellectual content, final approval of version to be published. Falcone, Aurucci, Tibaldi: acquisition of data, drafting article or revising it critically for important intellectual content, final approval of version to be published.

\section{Contributors}

Alessandro Reano, MD, Department of Medical Sciences, Città della Salute e della Scienza-Molinette, Torino, Italy.

\section{References}

[1] Khan IA. Clinical and therapeutic aspects of congenital and acquired long QT syndrome. Am J Med 2002 Jan;112(1):58-66.

[2] Heise W, Romero K, Woosley RL. QTDrugs Lists: AZCERT; 1999. (Available from): http://www.QTdrugs.orgAvailable from: https://crediblemeds.org/.

[3] Tisdale JE, Jaynes HA, Kingery JR, Mourad NA, Trujillo TB, Overholser BR, et al. Development and validation of a risk score to predict QT interval prolongation in hospitalized patients. Circ Cardiovasc Qual Outcomes 2013 Jul;6(4):479-87.

[4] Taneja T, Mahnert BW, Passman R, Goldberger J, Kadish A. Effects of sex and age on electrocardiographic and cardiac electrophysiological properties in adults. Pacing Clin Electrophysiol PACE 2001 Jan;24(1):16-21.

[5] Rautaharju PM, Mason JW, Akiyama T. New age- and sex-specific criteria for QT prolongation based on rate correction formulas that minimize bias at the upper normal limits. Int J Cardiol 2014 Jul 1;174(3):535-40.

[6] Mason JW, Ramseth DJ, Chanter DO, Moon TE, Goodman DB, Mendzelevski B. Electrocardiographic reference ranges derived from 79,743 ambulatory subjects. J Electrocardiol 2007 Jul;40(3):228-34.

[7] Akylbekova EL, Crow RS, Johnson WD, Buxbaum SG, Njemanze S, Fox E, et al. Clinical correlates and heritability of QT interval duration in blacks: the Jackson Heart Study. Circ Arrhythm Electrophysiol 2009 Aug;2(4):427-32.

[8] Kallergis EM, Goudis CA, Simantirakis EN, Kochiadakis GE, Vardas PE. Mechanisms, risk factors, and management of acquired long QT syndrome: a comprehensive review. ScientificWorldJournal 2012;2012:212178.

[9] Letsas KP, Efremidis M, Kounas SP, Pappas LK, Gavrielatos G, Alexanian IP, et al. Clinical characteristics of patients with drug-induced QT interval prolongation and torsade de pointes: identification of risk factors. Clin Res Cardiol Off J Ger Card Soc. 2009 Apr;98(4):208-12.

[10] Ungar A, Mussi C, Nicosia F, Ceccofiglio A, Bellelli G, Bo M, et al. The "syncope and dementia" study: a prospective, observational, multicenter study of elderly patients with dementia and episodes of "suspected" transient loss of consciousness. Aging Clin Exp Res 2015 Dec;27(6):877-82.

[11] Ungar A, Mussi C, Ceccofiglio A, Bellelli G, Nicosia F, Bo M, et al, Etiology of Syncope and Unexplained Falls in elderly adults with Dementia: Syncope and Dementia (SYD) study. J Am Geriatr Soc 2016 Aug;64(8):1567-73.

[12] Diagnostic and Statistical Manual of Mental Disorders. Text Revision. 4th Ed Washington, DC: American Psychiatric Association; 2000.

[13] Bazett HC. An analysis of time relations of electrocardiograms. Heart 1920;7:353-67.

[14] Darbar D, Kimbrough J, Jawaid A, McCray R, Ritchie MD, Roden DM. Persistent atrial fibrillation is associated with reduced risk of torsades de pointes in patients with drug-induced long QT syndrome. J Am Coll Cardiol 2008 Feb 26;51(8):836-42.

[15] Wagner GS, Macfarlane P, Wellens H, Josephson M, Gorgels A, Mirvis DM, et al. AHA/ACCF/HRS recommendations for the standardization and interpretation of the electrocardiogram: part VI: acute ischemia/infarction: a scientific statement from the American Heart Association Electrocardiography and Arrhythmias Committee, Council on Clinical Cardiology; the American College of Cardiology Foundation; and the Heart Rhythm Society. Endorsed by the International Society for Computerized Electrocardiology. J Am Coll Cardiol 2009 Mar 17;53(11):1003-11.

[16] Linn BS, Linn MW, Gurel L. Cumulative illness rating scale. J Am Geriatr Soc 1968 May;16(5):622-6.

[17] Conwell Y, Forbes NT, Cox C, Caine ED. Validation of a measure of physical illness burden at autopsy: the Cumulative Illness Rating Scale. J Am Geriatr Soc 1993 Jan;41(1):38-41. (Linn BS, Linn MW, Gurel).
[18] WHOCC - Guidelines for ATC classification and DDD assignment. Available from: https://www.whocc.no/news/guidelines_for_atc_classification_and_ddd_assignment

[19] Isbister GK, Page CB. Drug induced QT prolongation: the measurement and assessment of the QT interval in clinical practice. Br J Clin Pharmacol 2013 Jul;76(1):48-57.

[20] Pasquier M, Pantet O, Hugli O, Pruvot E, Buclin T, Waeber G, et al. Prevalence and determinants of QT interval prolongation in medical inpatients. Intern Med J 2012 Aug;42(8):933-40.

[21] Maison O, de la Gastine B, Dayot L, Goutelle S. Prevalence and Risk Factors of Drug Associated Corrected QT Prolongation in elderly Hospitalized patients: results of a Retrospective Analysis of Data Obtained over 6 months. Drugs Aging 2017 Jul;34(7):545-53.

[22] Vandael E, Vandenberk B, Vandenberghe Willems R, Foulon V. Risk factors for QTcprolongation: systematic review of the evidence. Int J Clin Pharmacol 2017 Feb;39(1):16-25.

[23] Schächtele S, Tümena T, Gaßmann KG, Fromm MF, Maas R. Co-Prescription of OTInterval Prolonging drugs: an Analysis in a large Cohort of Geriatric patients. PloS One 2016;11(5):e0155649.

[24] Rabkin SW. Impact of Age and sex on QT Prolongation in patients Receiving Psychotropics. Can J Psychiatry Rev Can Psychiatr. 2015 May;60(5):206-14.

[25] Zhang Y, Ouyang P, Post WS, Dalal D, Vaidya D, Blasco-Colmenares E, et al. Sexsteroid hormones and electrocardiographic QT-interval duration: findings from the third National Health and Nutrition Examination Survey and the Multi-Ethnic Study of Atherosclerosis. Am J Epidemiol 2011 Aug 15;174(4):403-11.

[26] Charbit B, Christin-Maître S, Démolis JL, Soustre E, Young J, Funck-Brentano C. Effects of testosterone on ventricular repolarization in hypogonadic men. Am J Cardiol 2009 Mar 15;103(6):887-90.

[27] Bidoggia H, Maciel JP, Capalozza N, Mosca S, Blaksley EJ, Valverde E, et al. Sex differences on the electrocardiographic pattern of cardiac repolarization: possible role of testosterone. Am Heart J 2000 Oct;140(4):678-83.

[28] Sohaib SMA, Papacosta O, Morris RW, Macfarlane PW, Whincup PH. Length of the QT interval: determinants and prognostic implications in a population-based prospective study of older men. J Electrocardiol 2008 Dec;41(6):704-10.

[29] Singh BN, Hollenberg NK, Poole-Wilson PA, Robertson JI. Diuretic-induced potassium and magnesium deficiency: relation to drug-induced QT prolongation, cardiac arrhythmias and sudden death. J Hypertens 1992 Apr;10(4):301-16.

[30] Brouillette J, Nattel S. A Practical Approach to avoiding Cardiovascular adverse Effects of Psychoactive Medications. Can J Cardiol 2017 Dec;33(12):1577-86.

[31] Beach SR, Celano CM, Noseworthy PA, Januzzi JL, Huffman JC. QTc prolongation, torsades de pointes, and psychotropic medications. Psychosomatics 2013 Feb;54(1):1-13

[32] Nielsen J, Graff C, Kanters JK, Toft E, Taylor D, Meyer JM. Assessing QT interval prolongation and its associated risks with antipsychotics. CNS Drugs 2011 Jun 1;25(6):473-90.

[33] Bouvy JC, Koopmanschap MA, Shah RR, Schellekens H. The cost-effectiveness of drug regulation: the example of thorough QT/QTc studies. Clin Pharmacol Ther 2012 Feb;91(2):281-8.

[34] Riad FS, Davis AM, Moranville MP, Beshai JF. Drug-Induced QTc Prolongation. Am J Cardiol 2017 Jan 15;119(2):280-3.

[35] Warnier MJ, Rutten FH, Souverein PC, de Boer A, Hoes AW, De Bruin ML. Are ECG monitoring recommendations before prescription of QT-prolonging drugs applied in daily practice? The example of haloperidol. Pharmacoepidemiol Drug Saf 2015 Jul;24(7):701-8.

[36] Pickham D, Helfenbein E, Shinn JA, Chan G, Funk M, Weinacker A, et al. High prevalence of corrected QT interval prolongation in acutely ill patients is associated with mortality: results of the QT in Practice (QTIP) study. Crit Care Med 2012 Feb;40(2):394-9.

[37] Nakanishi S, Yamada M, Hattori N, Suzuki G. Relation between QT duration and mortality in an elderly Japanese population. Am J Cardiol 2004 May 1;93(9):1182-5.

[38] Yap J, Jin AZ, Nyunt SZ, Ng TP, Richards AM, Lam CS. Longitudinal Communitybased Study of OT Interval and Mortality in Southeast Asians. PloS One. 2016;11(5):e0154901.

[39] De Bruyne MC, Hoes AW, Kors JA, Hofman A, van Bemmel JH, Grobbee DE. Prolonged QT interval predicts cardiac and all-cause mortality in the elderly. The Rotterdam Study. Eur Heart J 1999 Feb;20(4):278-84.

[40] Straus SMJM, Kors JA, De Bruin ML, van der Hooft CS, Hofman A, Heeringa J, et al Prolonged QTc interval and risk of sudden cardiac death in a population of older adults. J Am Coll Cardiol 2006 Jan 17;47(2):362-7.

[41] Odutayo A, Wong CX, Hsiao AJ, Hopewell S, Altman DG, Emdin CA. Atrial fibrillation and risks of cardiovascular disease, renal disease, and death: systematic review and meta-analysis. BMJ 2016 Sep 6;354:i4482.

[42] Sagie A, Larson MG, Goldberg RJ, Bengtson JR, Levy D. An improved method for adjusting the QT interval for heart rate the Framingham Heart Study. Am J Cardio 1992;70:797-801.

[43] Sri-On J, Tirrell GP, Bean JF, Lipsitz LA, Liu SW. Revisit, subsequent Hospitalization, Recurrent fall, and death within 6 months after a fall among elderly Emergency Department patients. Ann Emerg Med 2017 Oct;70(4):516-521.e2.

[44] Carpenter CR, Avidan MS, Wildes T, Stark S, Fowler SA, Lo AX. Predicting geriatric falls following an episode of emergency department care: a systematic review. Acad Emerg Med off J Soc. Acad Emerg Med 2014 Oct;21(10):1069-82.

[45] Pasqualetti G, Calsolaro V, Bini G, Dell'Agnello U, Tuccori M, Marino A, et al. Clinical differences among the elderly admitted to the emergency department for accidental or unexplained falls and syncope. Clin Interv Aging 2017;12:687-95.

[46] García-Fuertes D, Villanueva-Fernández E, Crespín-Crespín M. Drug-induced longQT and torsades de pointes in elderly polymedicated patients. Arq Bras Cardiol 2016 Feb;106(2):156-9. 